
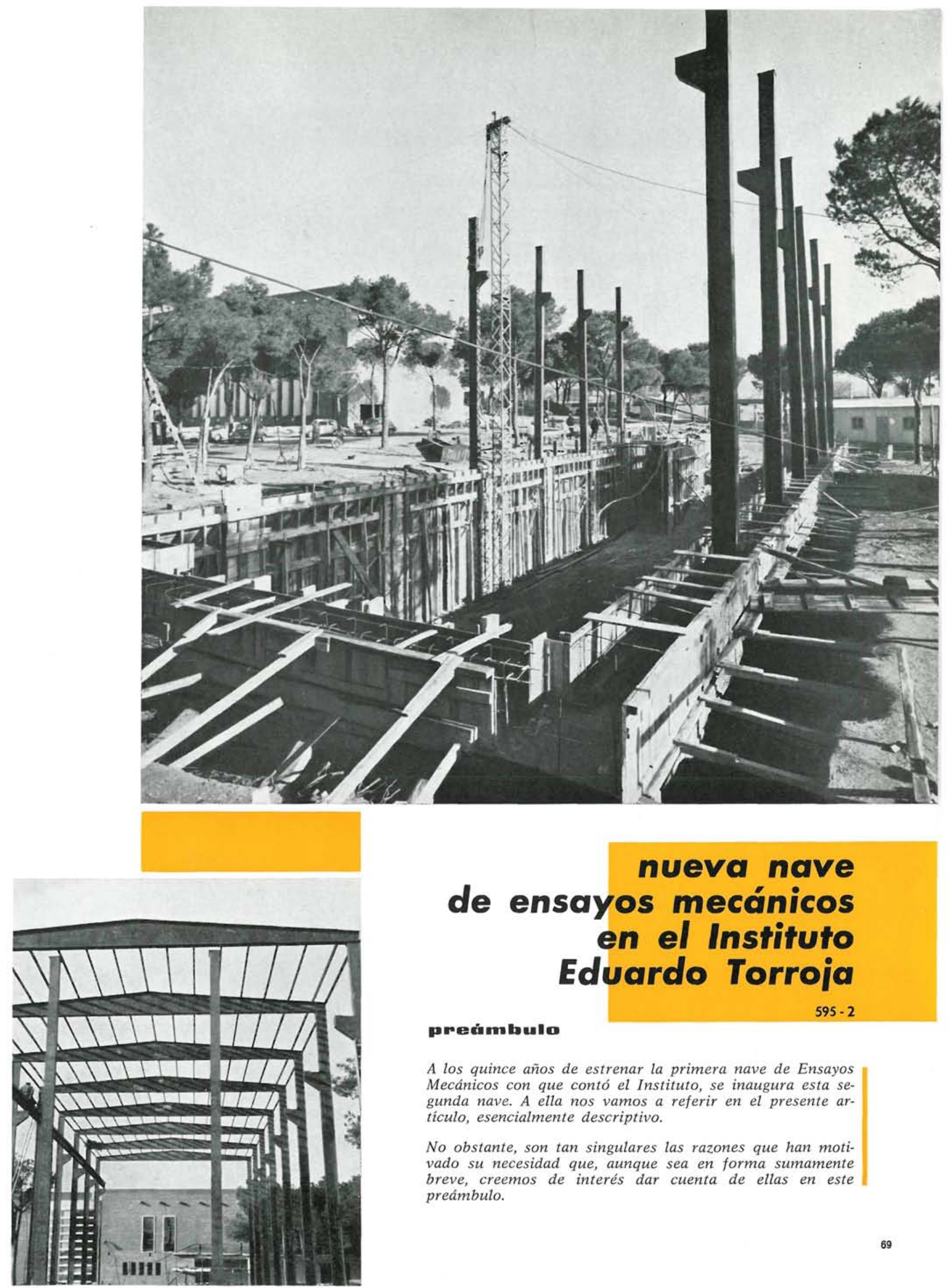

\title{
nueva nave de ensayos mecánicos en el Instituto Eduardo Torroja
}

\section{precinm bullo}

$595-2$

A los quince años de estrenar la primera nave de Ensayos Mecánicos con que contó el Instituto, se inaugura esta segunda nave. A ella nos vamos a referir en el presente artículo, esencialmente descriptivo.

No obstante, son tan singulares las razones que han motivado su necesidad que, aunque sea en forma sumamente breve, creemos de interés dar cuenta de ellas en este preámbulo. 

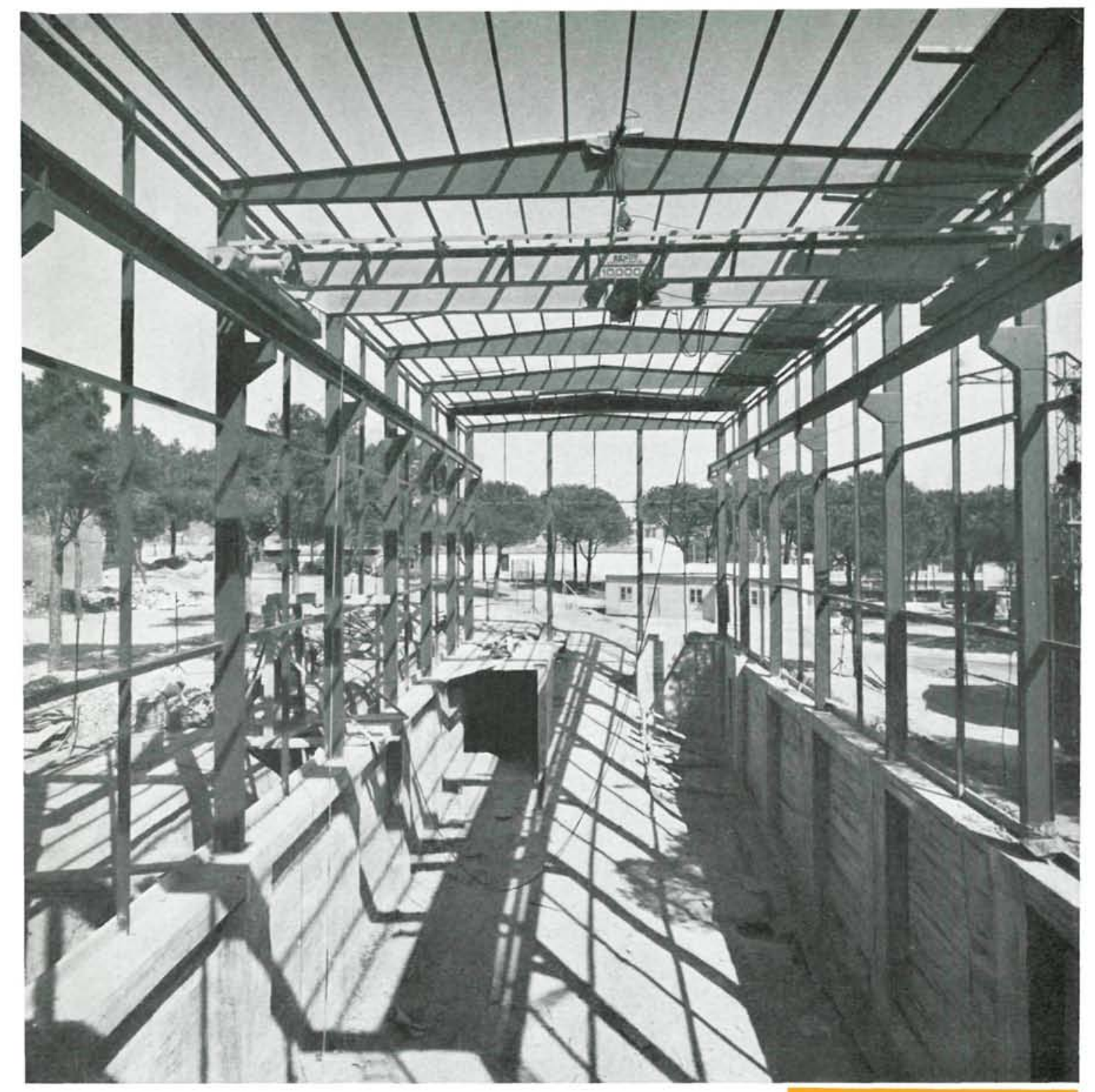

Cuando hace sólo quince años se inauguró la primera nave de Ensayos Mecánicos, la que hoy llamamos antigua, el Instituto, como decia nuestro Director en las palabras que pronunció al estrenar la nueva nave, podía sentirse orgulloso de contar con la nave de Ensayos Mecánicos mejor dotada de Europa, pues sólo existía entonces otra en servicio y era bastante más reducida.

Cabe, pues, intercalar, por ser tan evidente, que la inclusión de aquel elemento de trabajo en el programa de necesidades de las nuevas instalaciones que al fin, hace poco más de quince años, se conseguian levantar como sede propia del Instituto dice no poco de la amplitud de visión de futuro, de los que apoyaron y defendieron la idea planteada por Torroja.

Pues bien, en sólo quince años lo que parecía exagerado y para muchos absurdo, lo que para algunos era un alarde innecesario, por su exorbitada previsión, ha quedado tan corto y escaso de posibilidades que ya no era apto ni servía
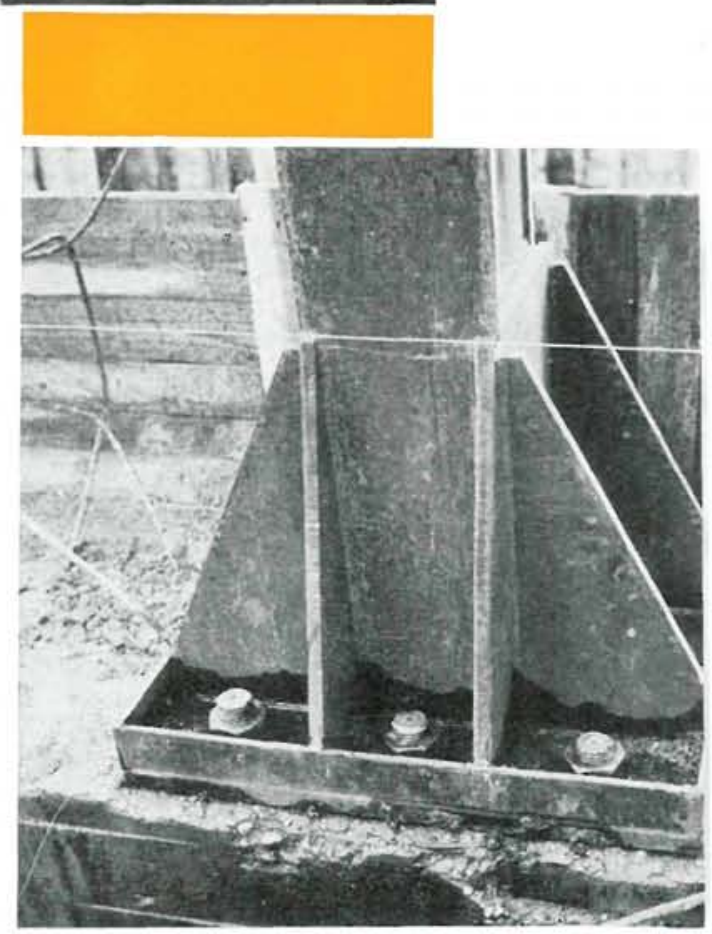


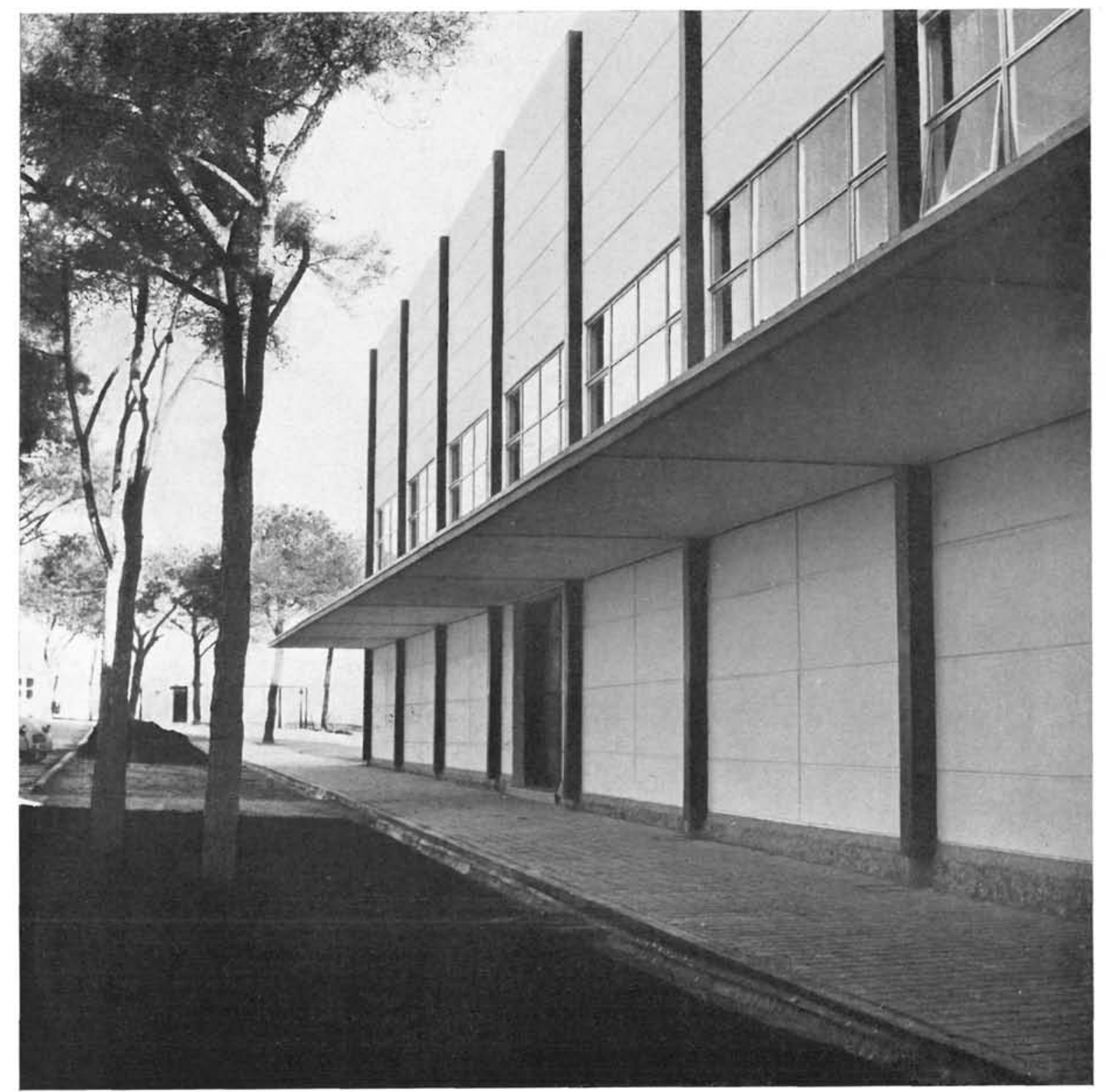

para un número importante de ensayos, necesarios para nuestras propias investigaciones, ni para un número, aún mayor, de ensayos solicitados por la Industria.

Puede afirmarse que sólo a los cinco años de construida, la primera nave trabajaba ya a pleno rendimiento y en muchos casos empezaba a ser rebasada en sus posibilidades por las crecientes peticiones de la Industria.

A partir de entonces, la aceleración de procesos se multiplica en un continuado avance científico-tecnológico. El progreso matemático, las posibilidades de los computadores, el paso a las formulaciones exactas que empiezan a ser posibles, los nuevos métodos de cálculo, toda esta cadena hace que, en un plazo tan estricto, las cargas de $7 t$ por punto admisibles en la primitiva nave y susceptibles de multiplicarse enlazando varios puntos mediante la aplicación de dispositivos adecuados, se fijen en la nueva nave, mediante un proceso razonado y lógico, en 50 y 100 t por punto que, del mismo modo, también pueden agruparse, alcanzando, como es fácil de comprender, cifras verdaderamente importantes. 


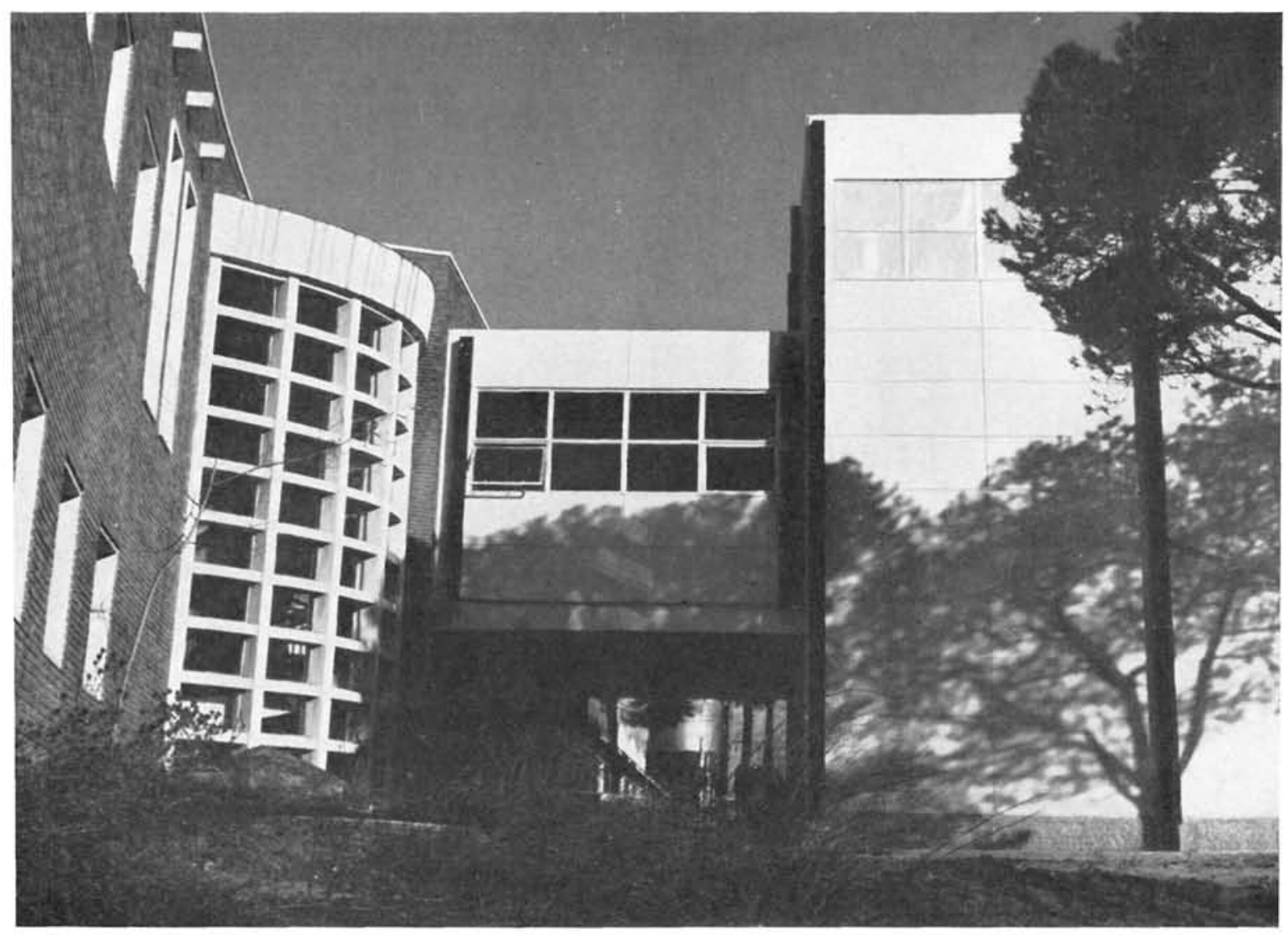

Este vertiginoso y casi explosivo avance de todos los procesos cientificos y paralelamente tecnológicos, es lo que deseábamos señalar. La progresión de necesidades planteadas a la nueva nave en un lapso de tiempo tan breve proporciona un ejemplo tan sumamente gráfico de las singulares circunstancias que rodean esta etapa que nos corresponde vivir, que no hemos querido dejar de subrayarlo.

Volviendo al objeto de estas notas, y en conformidad con lo expuesto, la Dirección del Instituto sentia la acuciante preocupación de resolver definitivamente la evidente necesidad de disponer de una nueva nave, capaz de admitir holgadamente los ensayos en curso y los aún no abordados por incapacidad de la nave existente, dotándola de unos márgenes suficientes para poder absor. ber los esfuerzos previsibles en un futuro próximo.

En esta idea se proyectó la nueva nave, en la que se consideraron multitud de detalles, producto de la experiencia adquirida durante el servicio de la primera.

En ella se crea el sótano, que abre todo género de posibilidades a la programación de ensayos independientes, tanto sobre la losa como bajo la misma, o, lo que es más importante, estableciendo interdependencias con acciones comunes; se cuida el acceso de vehículos pesados a nave y sótano; se prevé la posibilidad de dos puentes-grúa para movimientos y montajes especiales; se dimensiona el volumen de la nave con la capacidad más adecuada a las funciones que se piensa realizar; se cuida la intensidad luminosa y se evita el deslumbramiento; se crea un original dispositivo de anclajes que permite la directa y múltiple comunicación de nave y sótano; se deja libre acceso al puente-grúa para bajar o elevar lo que se precise de la nave al sótano y viceversa; $y$ asi, en esta linea, se estudian multitud de detalles, en base a toda la problemática planteada a lo largo de los diferentes tipos de trabajos estudiados, pero sobre los que no se desea entrar con demasiado detalle para no alargar excesivamente el presente articulo descriptivo.

Pasamos, por tanto, a concretar únicamente los principales extremos que se ha considerado deben tratarse con mayor extensión. 


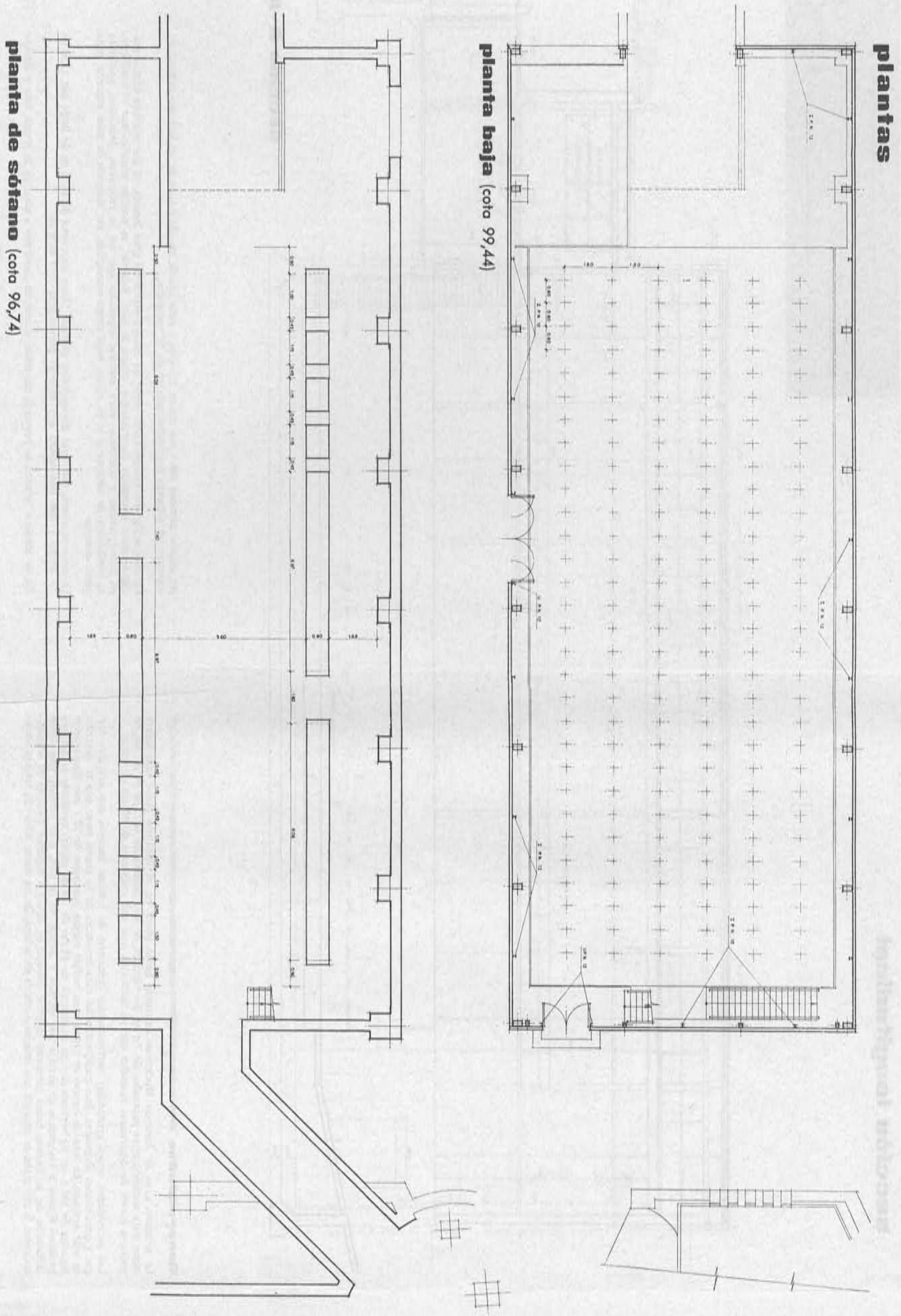



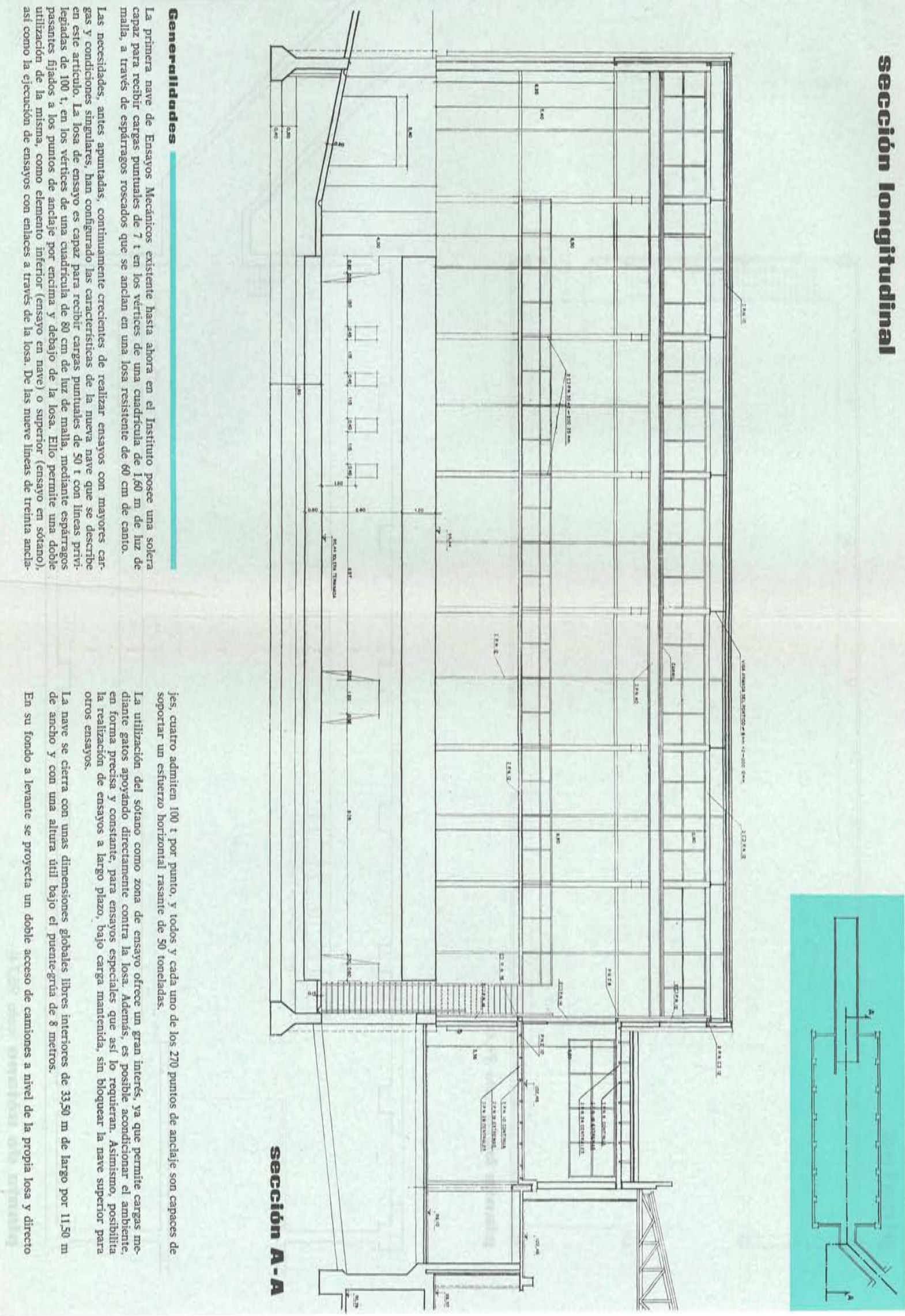


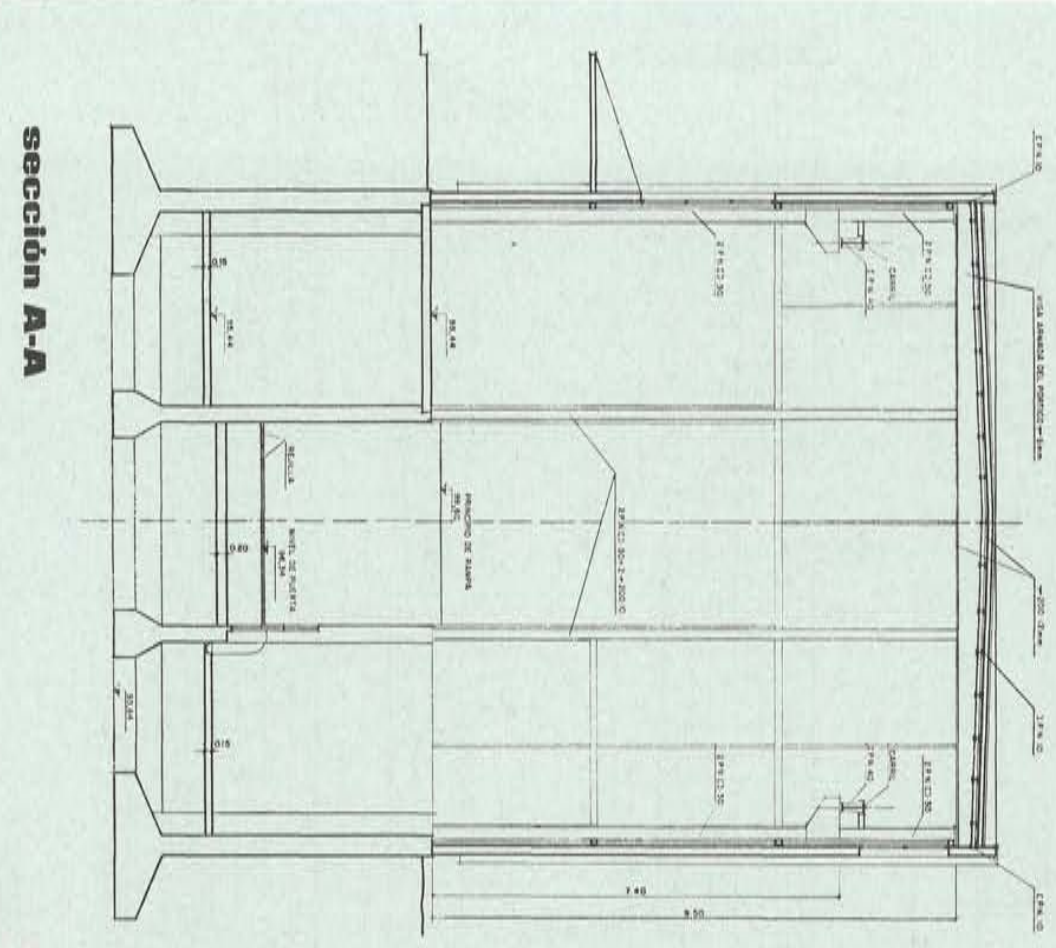

ํㅜㄹ
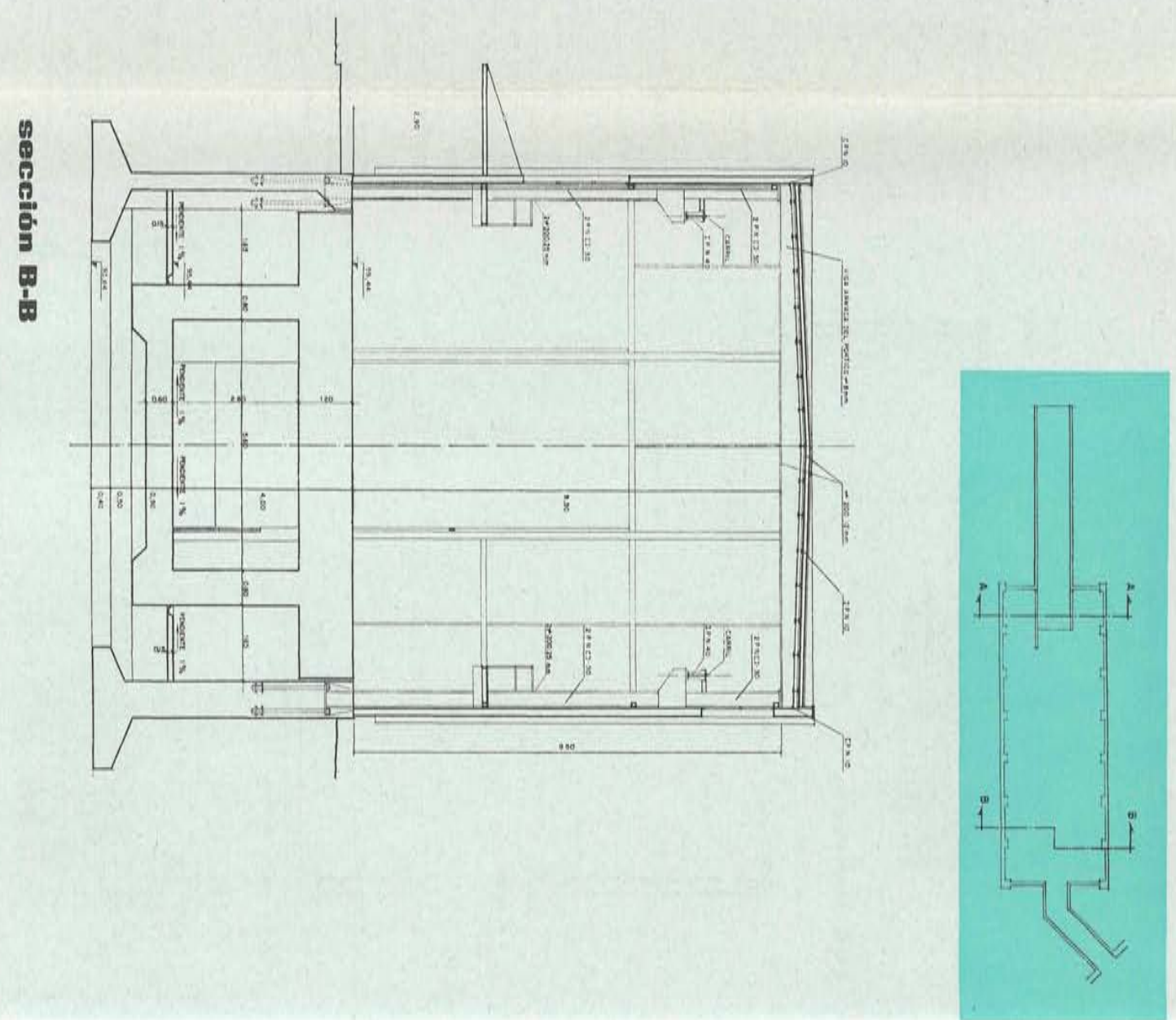

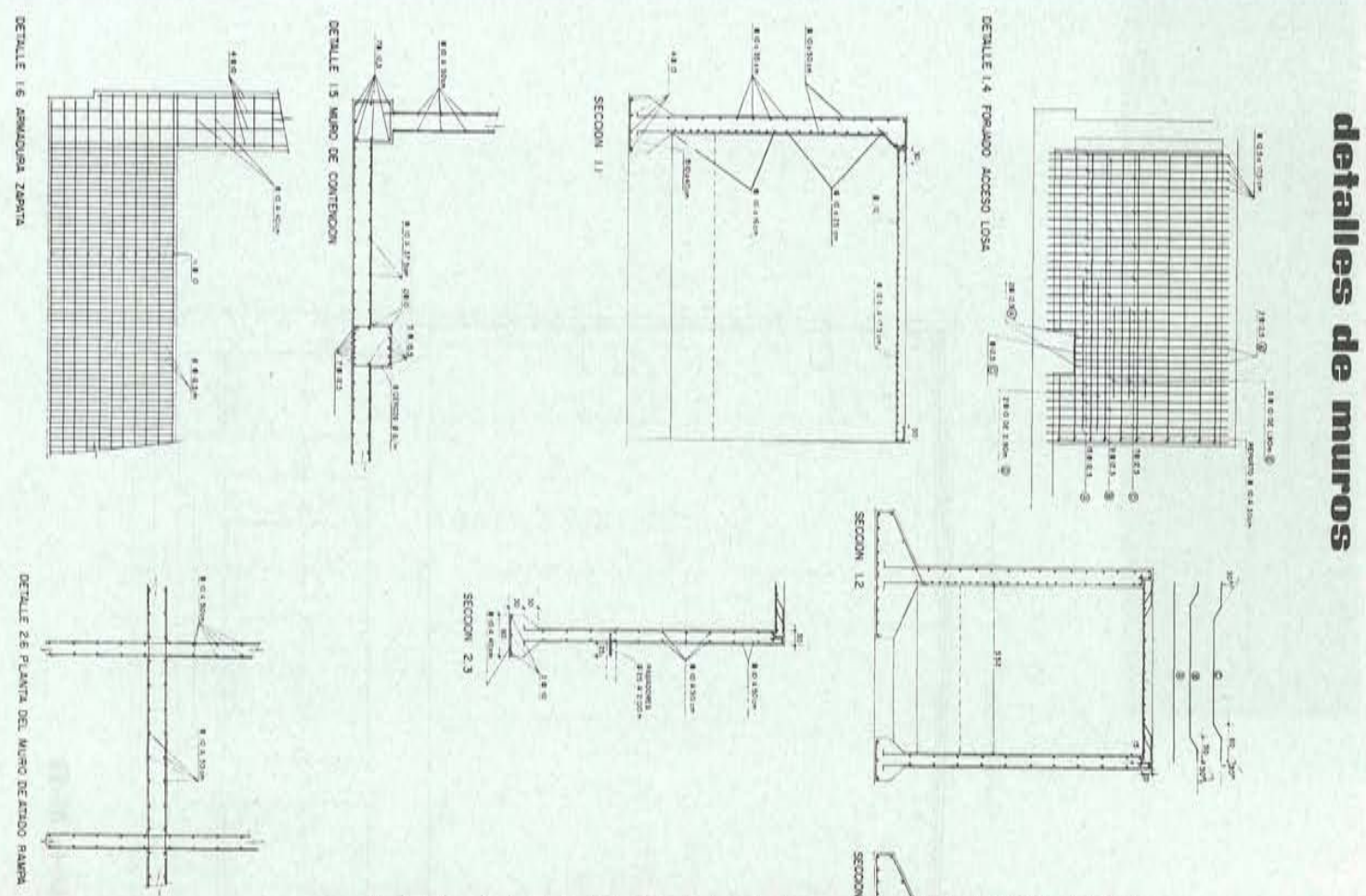

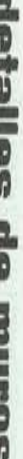
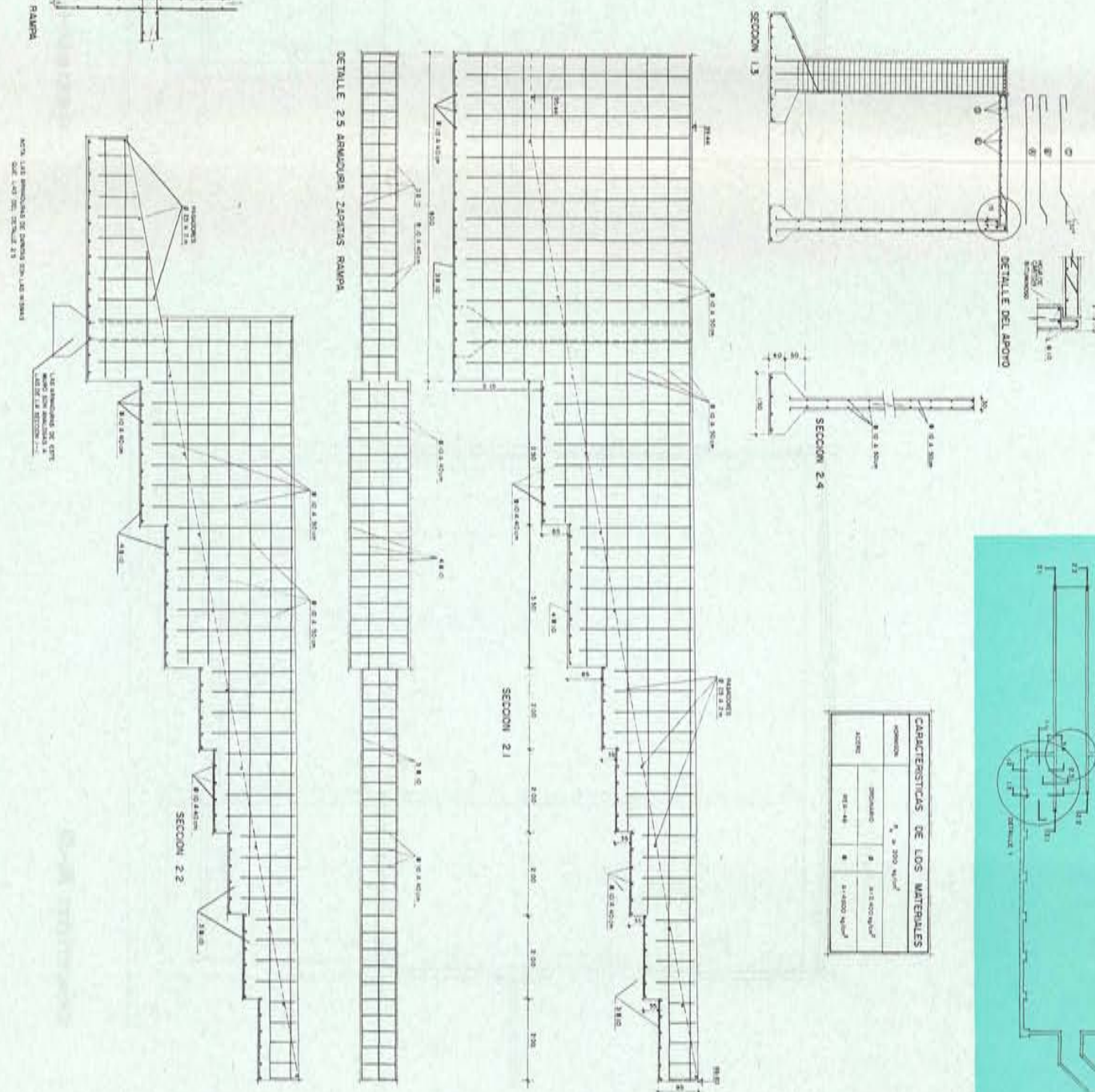

$+40+10$

:
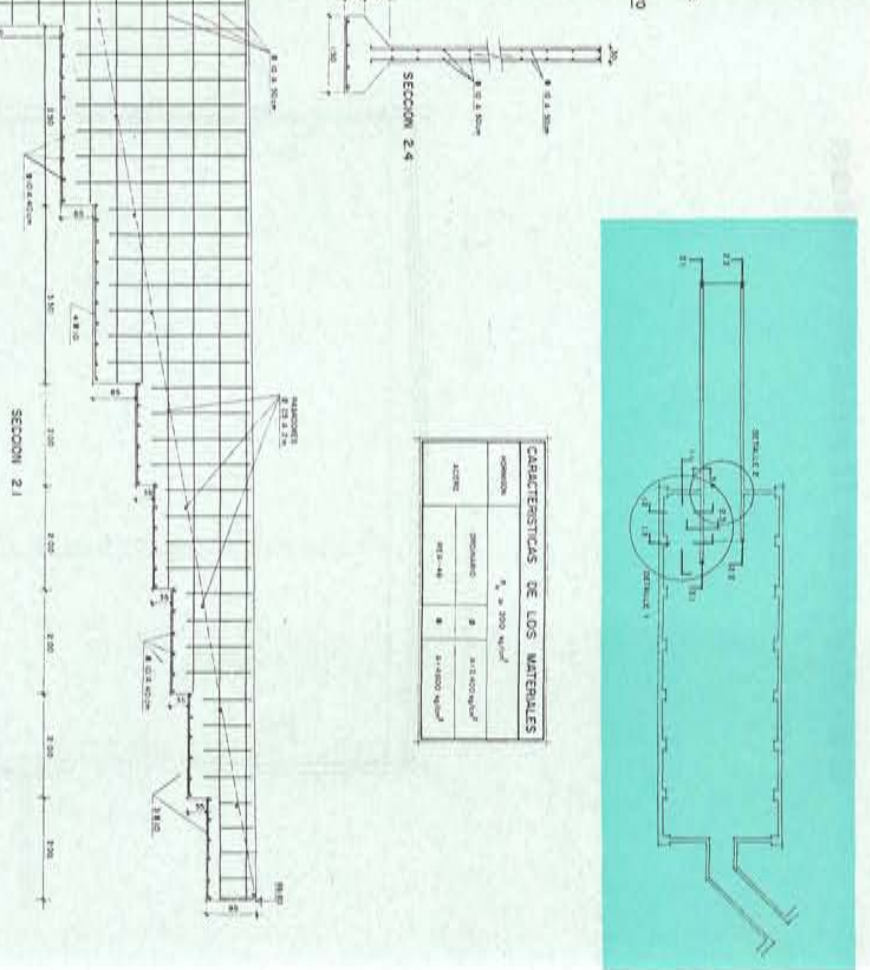

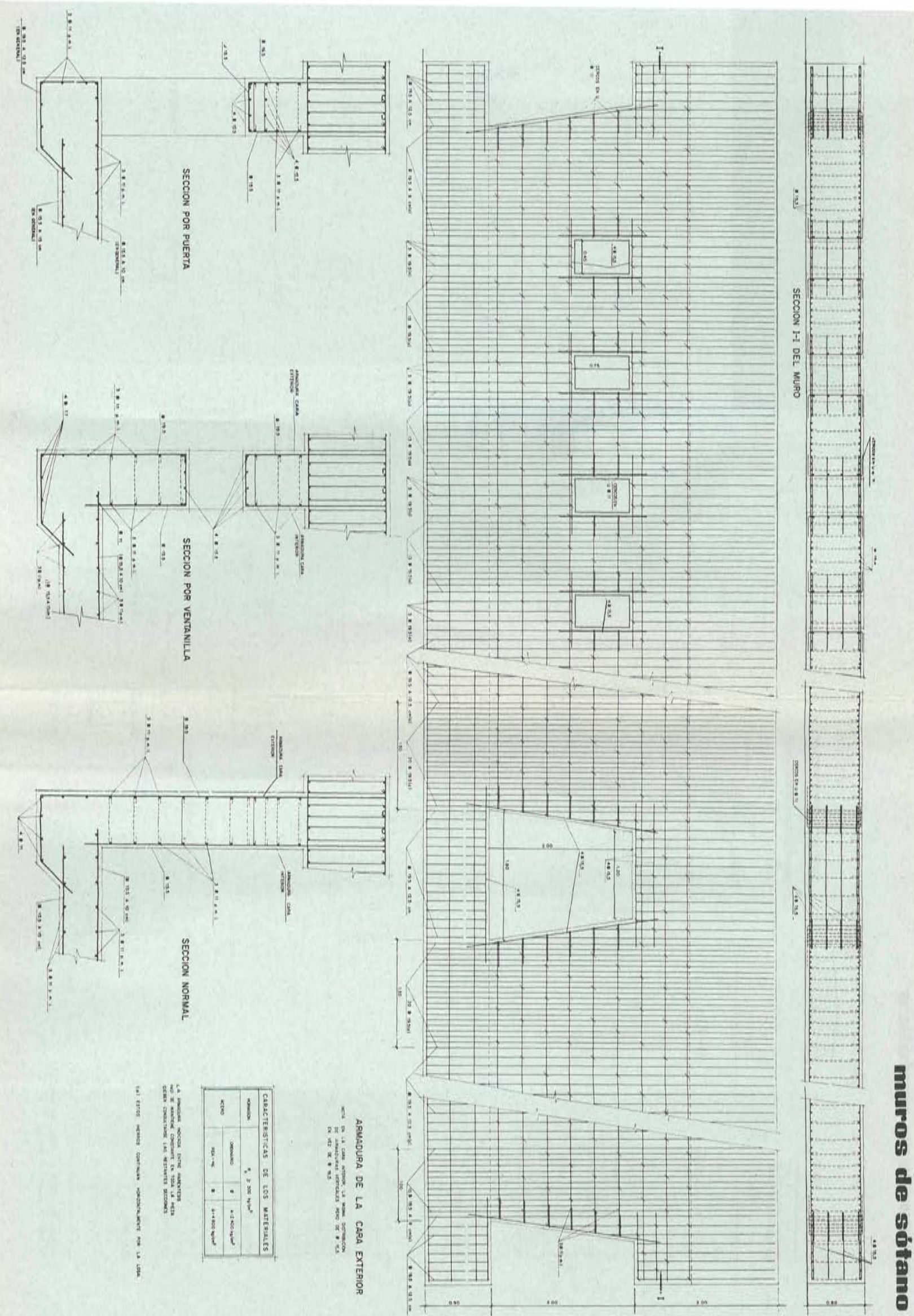

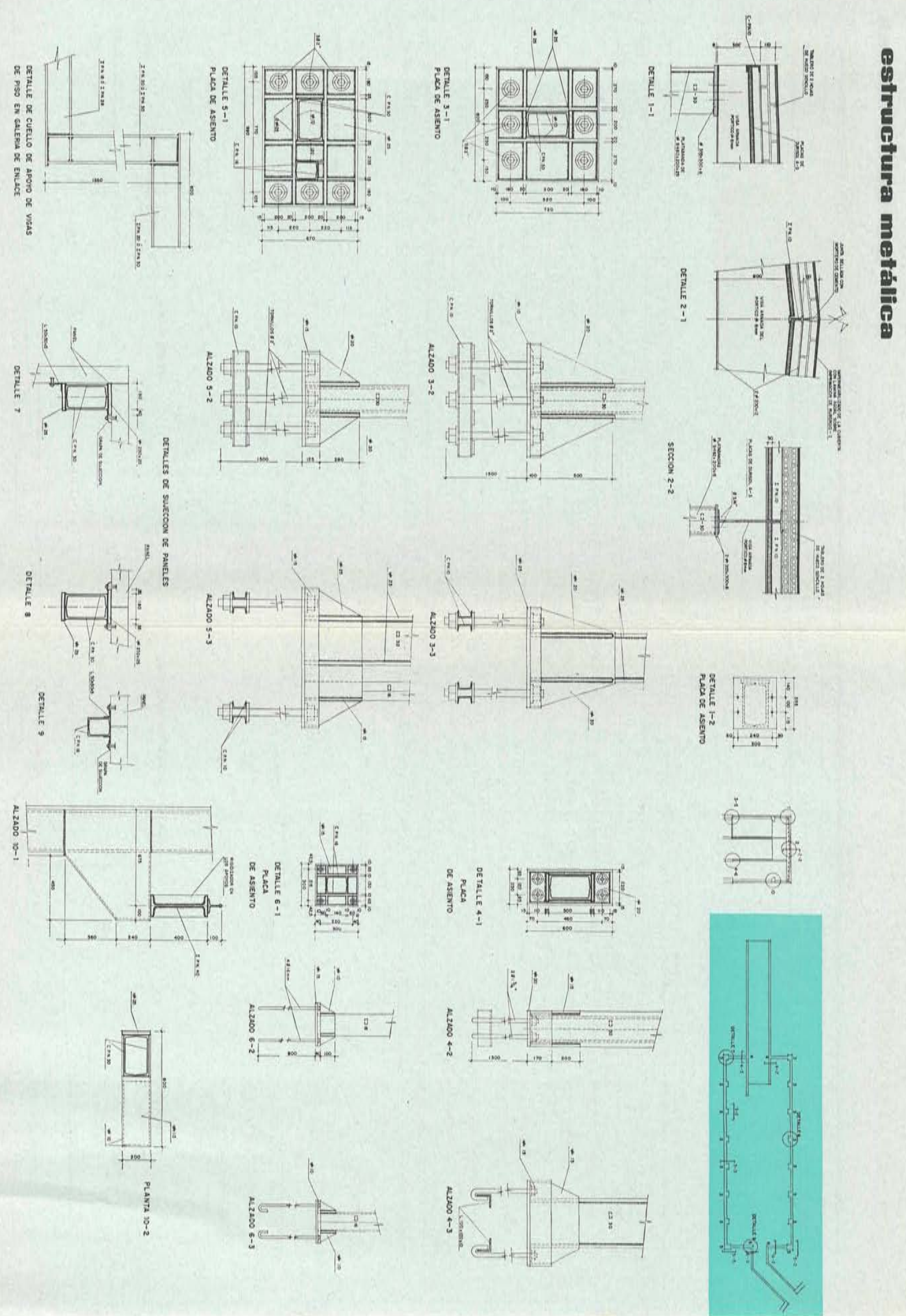
a sótano, dejándose un espacio suficiente para la comunicación vertical con el puente-grúa entre ambos recintos.

La luz natural se orienta principalmente a norte, con una línea de refuerzo en la zona más elevada de la fachada a mediodía, suprimiéndose los ventanales bajos para evitar contraluces, especialmente enojosos en las operaciones de los ensayos.

La nave está dotada de equipos AMSLER, capaces de proporcionar una amplia gama de cargas estáticas y dinámicas para la ejecución de ensayos de todo tipo, sometidos a programas de trabajo similares a las cargas reales, mayoradas en la medida que se considere.

\section{Descmipción de Ia Iosa}

La losa de ensayos tiene unas dimensiones en planta de $10,50 \mathrm{~m} \times 25,50 \mathrm{~m}$, con sección transversal en forma de cajón. La losa propiamente dicha constituye el dintel del cajón y tiene un espesor de $1,20 \mathrm{~m}$, siendo $0,60 \mathrm{~m}$ el espesor de la inferior y $0,80 \mathrm{~m}$ el de los muros.

El conjunto está totalmente independizado del resto de la estructura de la nave, con objeto de evitar la transmisión de eventuales vibraciones debidas a ensayos dinámicos.

Todos los elementos antedichos, solera, muros y losa superior, son de hormigón armado. La losa posee nueve filas longitudinales de treinta anclajes cada una.

\section{Anclajes}

Cada anclaje está constituido por un tubo de acero de $131 \mathrm{~mm}$ de diámetro interior y espesor de pared de $4,5 \mathrm{~mm}$, terminado en sendas placas mecanizadas de acero, en forma de corona circular, de $20 \mathrm{~mm}$ de espesor. A tales cabezas se sueldan unos ganchos de anclaje de redondo $\varnothing 20$ de acero dulce.

Con anterioridad a la construcción de la losa se ensayaron dos prototipos de anclaje, embebidos en cilindros de hormigón de $0,90 \mathrm{~m}$ de diámetro y $1,20 \mathrm{~m}$ de altura. Los ensayos demostraron que el comportamiento del anclaje era correcto, con recuperación total hasta una carga vertical de $200 \mathrm{t}$ y horizontal de $50 \mathrm{t}$. El coeficiente de seguridad a rotura, respecto a la carga máxima prevista de $100 \mathrm{t}$ en ciertos anclajes (los situados junto a los muros verticales), resultó ligeramente superior a 5 .

\section{Gálaulo de la Iosa}

El cálculo se realizó con ayuda del computador electrónico del Instituto. En primer lugar, se consideraron separadamente las dos hipótesis extremas de coacción en los encuentros muro-dintel, es decir, empotramiento perfecto y apoyo simple, con los otros dos bordes de la losa libres, y se estudiaron los esfuerzos resultantes de aplicar, en cada hipótesis, una carga de $50 \mathrm{t}$ en los distintos puntos de anclaje. A continuación se estudió una rebanada del cajón, supuesto apoyado en un macizo elástico, con dos valores extremos del módulo de reacción, asimilando el terreno, a efectos del cálculo electrónico, a una serie de pilares de rigidez nula y tales que su deformación longitudinal fuese la misma que la del terreno.

De los resultados de los estudios anteriores se dedujo, para cada hipótesis de carga y para cada hipótesis de coacción, la relación entre el momento flector máximo en la rebanada y el momento flector total en la losa, relación que resultó del orden de 0,15 . Ello permitió pasar de los estados de carga reales en la losa a los ficticios equivalentes en la rebanada. Así, por ejemplo, una serie de seis cargas de $50 \mathrm{t}$ dispuestas en dos filas equivalían, en el estudio de la rebanada, a dos cargas de 20 toneladas.

De la forma descrita se determinaron los máximos momentos en cada zona del cajón, dimensionándose las armaduras correspondientes. Las hipótesis de carga estudiadas cubren todas las posibilidades de ensayos simultáneos, tanto para elementos cortos como para elementos largos. El momento máximo de servicio resultó de 60 metros tonelada por metro, al que se aplicó un coeficiente de mayoración de 1,65. Las armaduras son casi simétricas, con objeto de permitir el empleo indistinto de la nave o del sótano para dar cargas contra la losa. La pequeña diferencia de simetría se debe a la actuación del peso propio. 

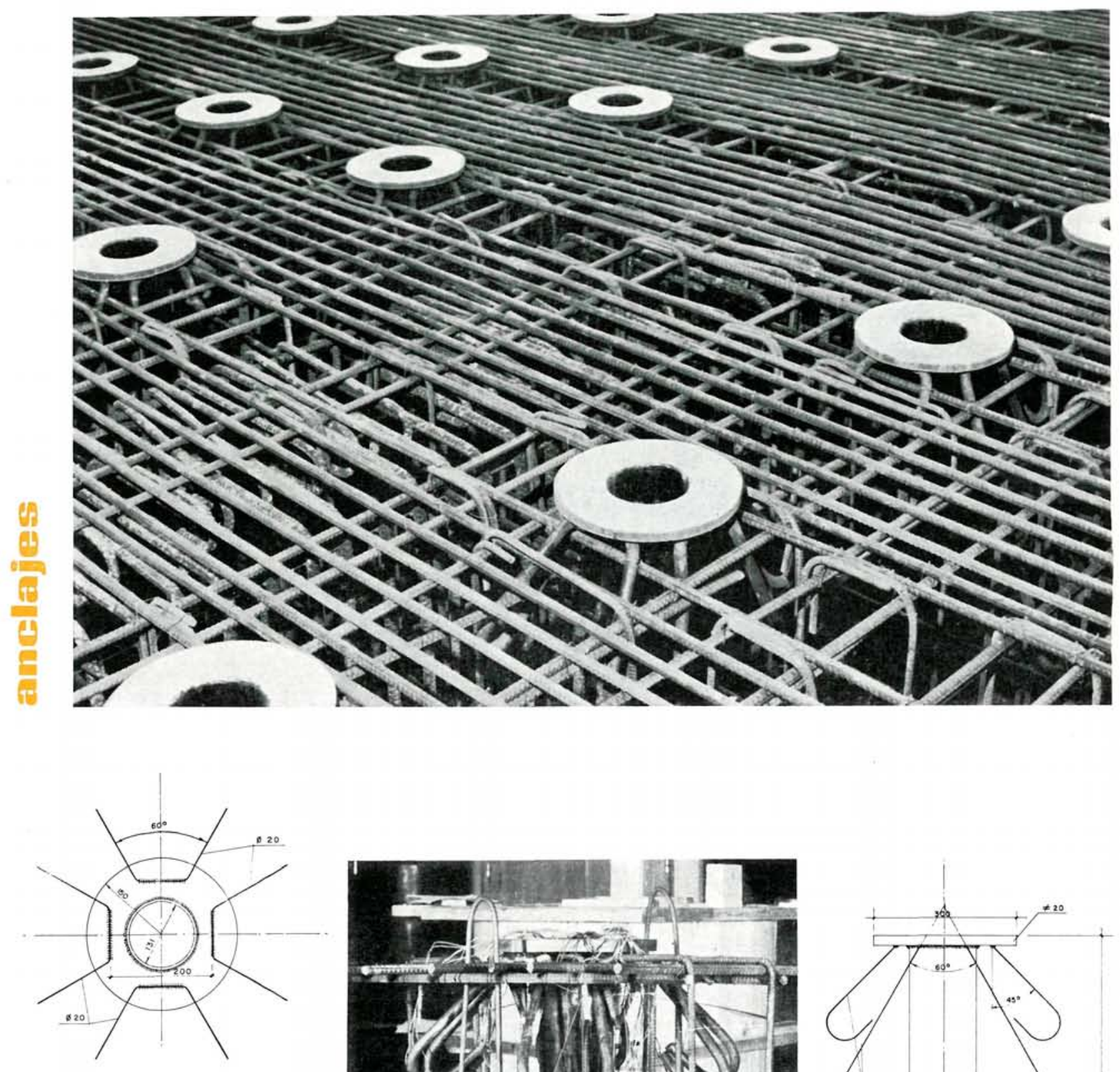

ensagyo
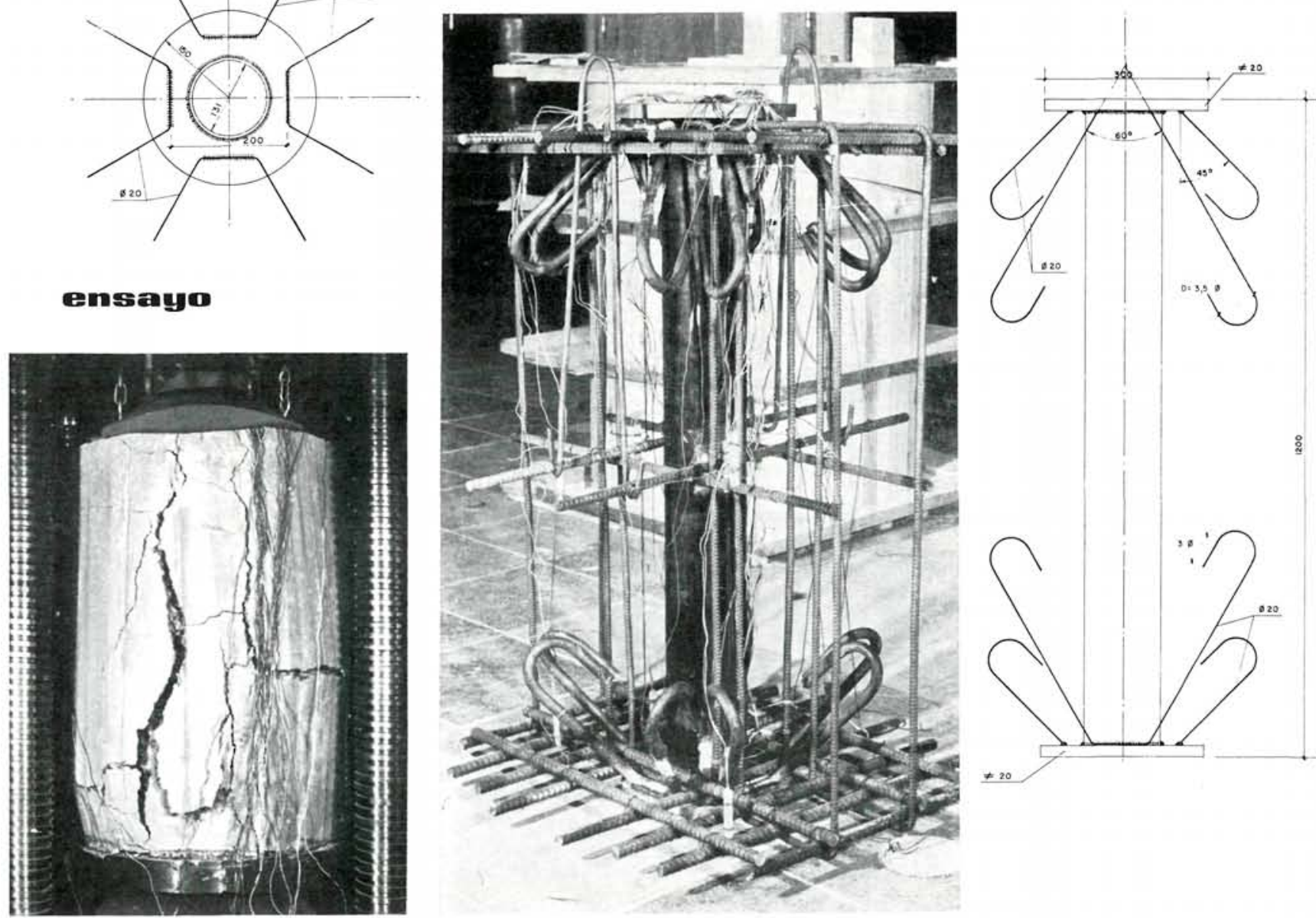


\section{Murros ale sónten}

En los muros longitudinales de sótano, se han dispuesto aberturas convenientemente reforzadas para poder montar en ellas ensayos de carga mantenida y realizar estudios de cualquier tipo sin estorbar otros espacios. Las testas de los muros van igualmente reforzadas y permitirán utilizar el sótano como bancada de pretensado, contando con los muros como elemento resistente en dirección longitudinal.

\section{Est?}

Se eligió una estructura que fuese fácil de construir y montar. Modulada a $4,80 \mathrm{~m}$, está formada por unos pilares en cajón de $9,50 \mathrm{~m}$ de altura, sobre los que apoyan unas vigas armadas de canto variable de $11 \mathrm{~m}$ de luz. Estas vigas reciben unas correas formadas por perfiles IPN 10, sobre los que se encajan las placas prefabricadas de cerramiento.

Cada soporte de la estructura va anclado al muro perimetral de hormigón que cierra el sótano, mediante seis anclajes $\varnothing 2$ ". La nave se ha previsto para usar dos puentes-grúa de $10 \mathrm{t}$, aun cuando por el momento se ha montado sólo uno, que cubre las necesidades actuales.

Las vigas para rodadura de los puentes están formadas por dos perfiles: una IPN 40 y una $\sqsubset$ PN 25/10 para absorber las flexiones horizontales. El apoyo de estas vigas sobre los pilares se realiza a través de unas ménsulas.

Para sujeción de los paneles prefabricados que constituyen el cerramiento de la nave, existe una estructura secundaria formada por pilares cerrados compuestos por $2 I_{-}^{-} 16$.

Con objeto de facilitar la observación y manipulación de los ensayos y realizar montajes accesorios, toma de fotografías, etc., a lo largo de la nave se ha construido una pasarela volada que la rodea a una altura conveniente.

\section{Gerreguniemento}

El cerramiento de la nave se realizó con elementos prefabricados de hormigón, eligiéndose el sistema LECA (sigla de la designación inglesa «light expanded clay aggregate») para la construcción de los paneles.

Las características técnicas de este material preparado a base de arcillas especiales, son aptas para dotar al cerramiento de las propiedades que debe poseer una construcción de la índole de una nave de ensayos.

El grano de este hormigón ligero presenta una estructura en forma de panal de abejas, que confiere al elemento un poder aislante elevado y constante. En estado seco, los paneles poseen un coeficiente de conductibilidad térmica inferior a $0,24 \mathrm{kcal} / \mathrm{m} \cdot \mathrm{h} \cdot{ }^{\circ} \mathrm{C} \mathrm{y}$, al contrario de lo que sucede con otros materiales que absorben muy rápidamente la humedad, perdiendo, por consiguiente, su poder aislante, es sumamente impermeable. De esta impermeabilidad procede la gran resistencia al hielo de los paneles. Esta propiedad ha sido reforzada gracias al revestimiento de aquéllos. También fue considerado su carácter incombustible. Según puede verse en las secciones representadas, la constitución de los paneles, de dentro afuera, es un núcleo de $16 \mathrm{~cm}$ de hormigón LECA de $250 \mathrm{~kg} / \mathrm{m}^{3}$, un revestimiento de $2 \mathrm{~cm}$ de mortero de arena y cemento blanco de $400 \mathrm{~kg} / \mathrm{cm}^{3}$, y una capa de pintura a base de siliconas. Sus dimensiones son de $240 \times 80 \mathrm{~cm}$.

Diversos prototipos de paneles fueron ensayados previamente con el fin de comprobar la idoneidad de sus características. En particular, los ensayos de resistencia al choque evidenciaron la conveniencia de reforzar los elementos con una malla electrosoldada, en previsión de los impactos excepcionales que pueden presentarse en la nave.

Con objeto de evitar las vibraciones, acusables especialmente durante el funcionamiento del puentegrúa, se dispusieron unos tacos de goma entre el intradós de los paneles y los perfiles que constituyen los soportes metálicos de la estructura de la nave. En los detalles representados figuran las secciones correspondientes a los dos tipos de soportes existentes, así como a los elementos de esquina. 


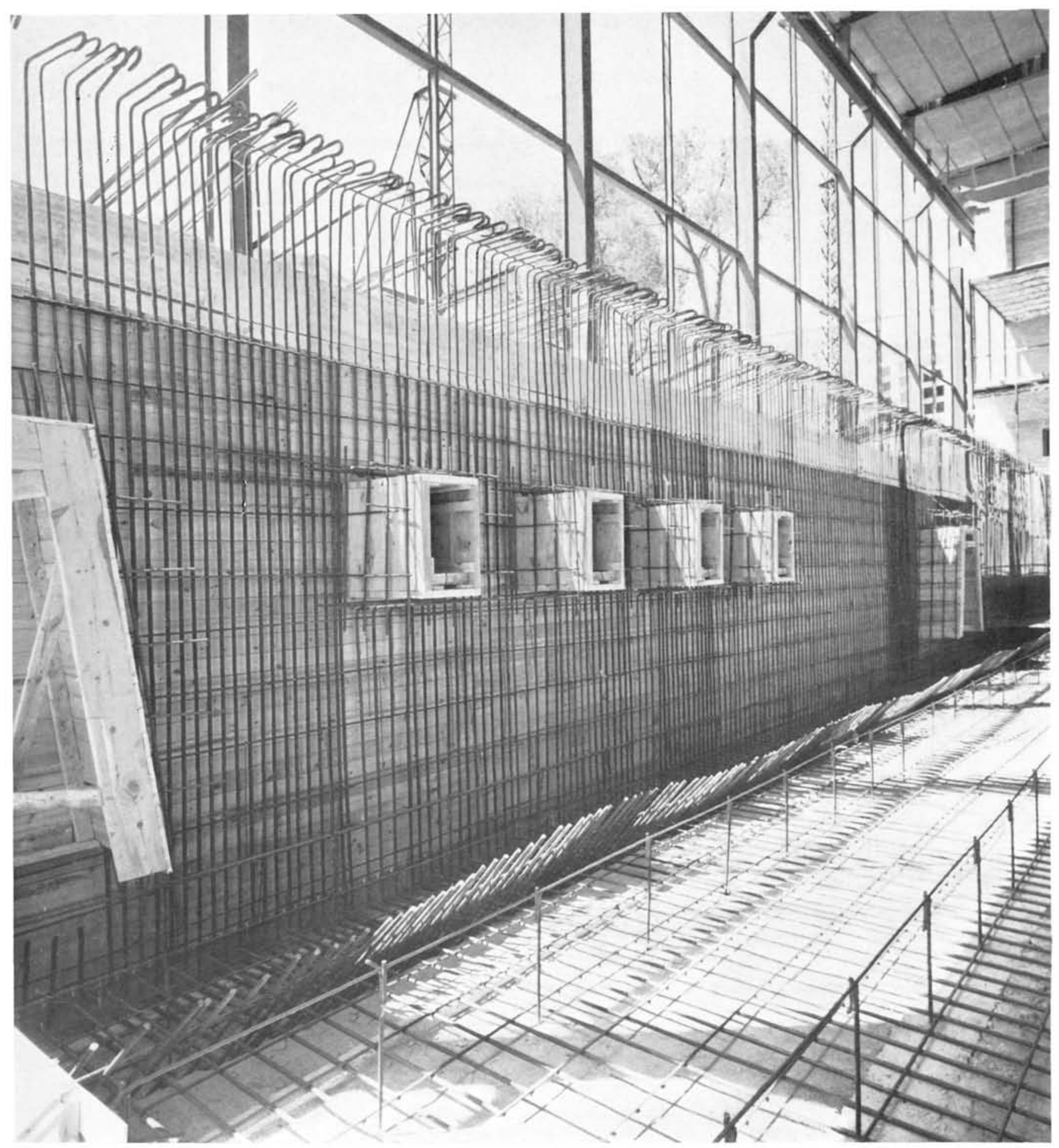

El problema de las juntas, esencial en esta clase de construcciones, fue estudiado, con particular atención, sobre diversos prototipos del I.E.T. y de países con mayor experiencia en el tema, eligiéndose finalmente la forma adoptada como de mayor garantía aislante-resistente.

El relleno de las juntas verticales está realizado con el mismo hormigón de constitución de los paneles, vertido in situ. Las dimensiones de la sección de la junta son, conforme a las Normas, suficientes para asegurar buenas condiciones de endurecimiento. La estanquidad se consigue mediante una banda de fieltro de $25 \mathrm{~mm}$ a todo lo largo de la junta. 


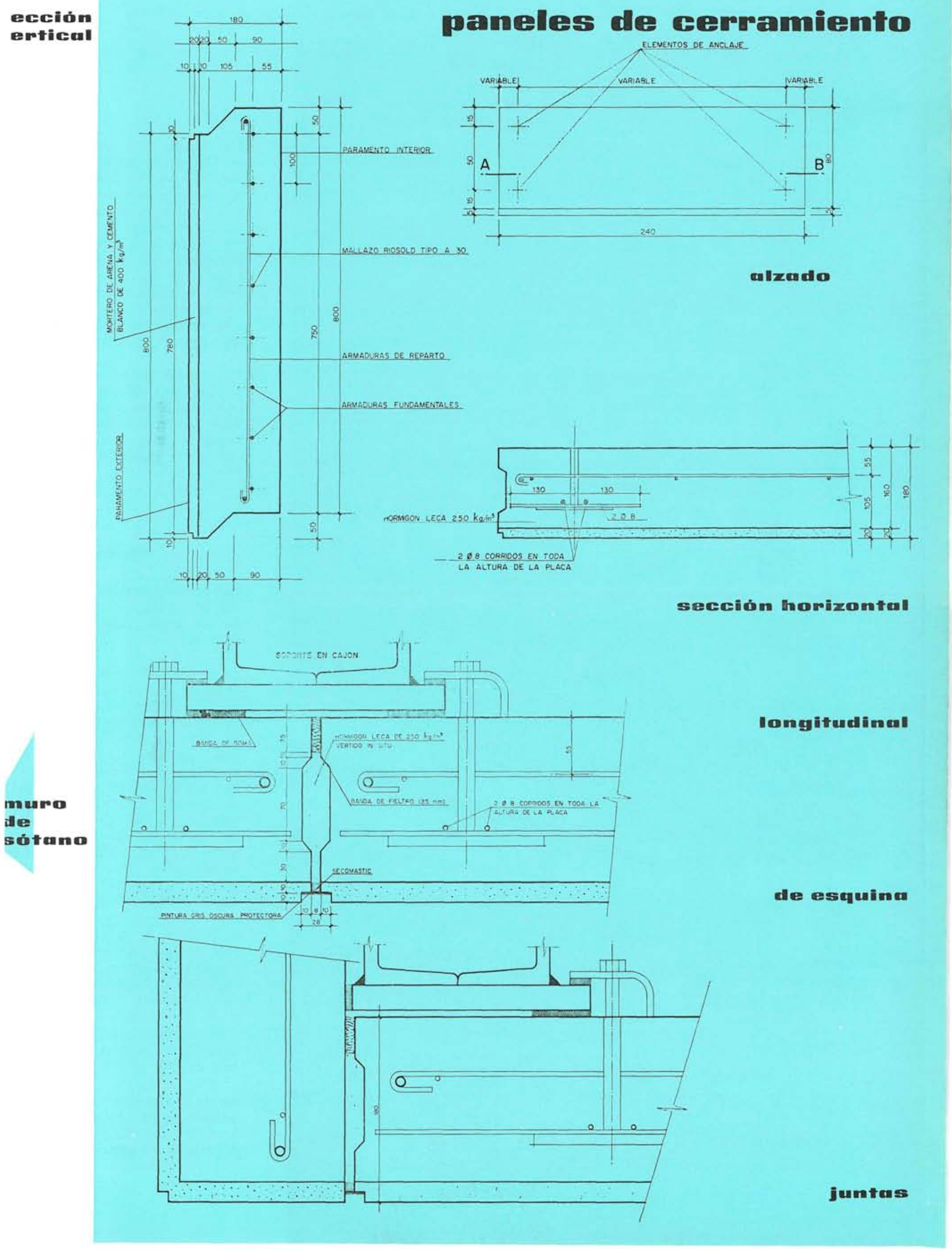



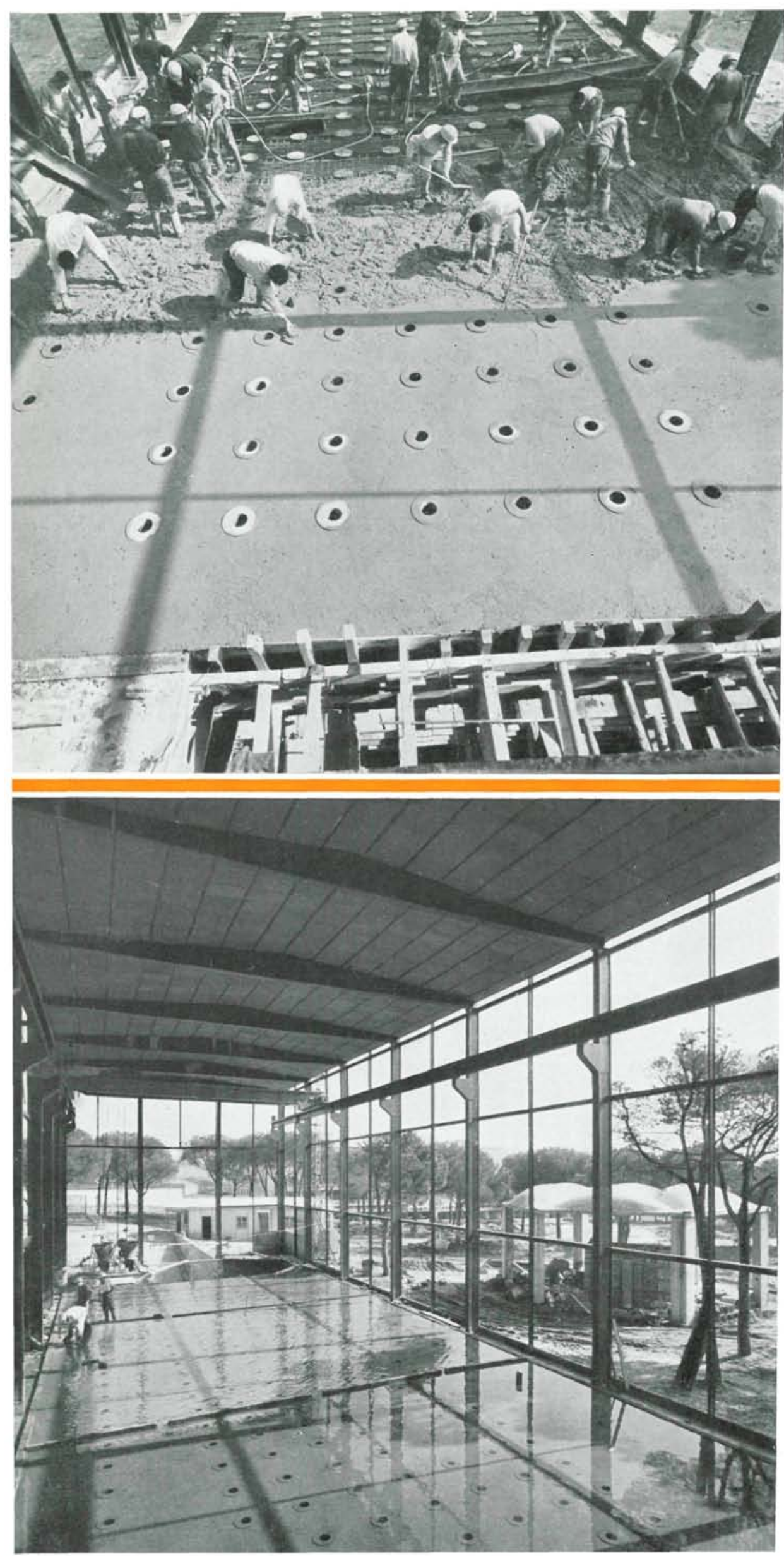

En cuanto a la estanquidad de las juntas horizontales, se obtiene por la configuración de los extremos de los paneles, y la introducción de una banda de fieltro y de una lía embreada para obturar ambos bordes de la junta. En el trasdós de los paneles, el relleno de la unión entre paneles se efectúa con un mástique, recubierto a su vez por una pintura protectora.

La fijación de los paneles se llevó a cabo con pernos de anclaje reglables, aislados tam. bién convenientemente por medio de tacos de goma, con objeto de eliminar las vibraciones.

\section{Ejecución}

Las principales líneas de actuación y etapas seguidas en la ejecución fueron las siguientes:

Se construyó primero la nave propiamente dicha, es decir, los muros de cimentación y la estructura metálica, con el fin de poder montar el puentegrúa, para su utilización como principal elemento auxiliar en la delicada operación de hormigonado de la losa. Luego, y con la ayuda de éste, se hormigonó el cajón resistente en tres etapas: solera, muros y losa de ensayo; y por último, se montó el cerramiento lateral y la cubierta.

Para evitar la excesiva retracción y calor de fraguado se empleó un cemento portland P-350. El hormigón se preparó en central y fue suministrado en camiones hormigonera, superando todas las probetas la resistencia característica exigida de $350 \mathrm{~kg} / \mathrm{cm}^{2}$.

Es de destacar que el hormigonado de la losa propiamente dicha, con un volumen de hormigón de unos $325 \mathrm{~m}^{3}$, se 


\section{juntas verticales}

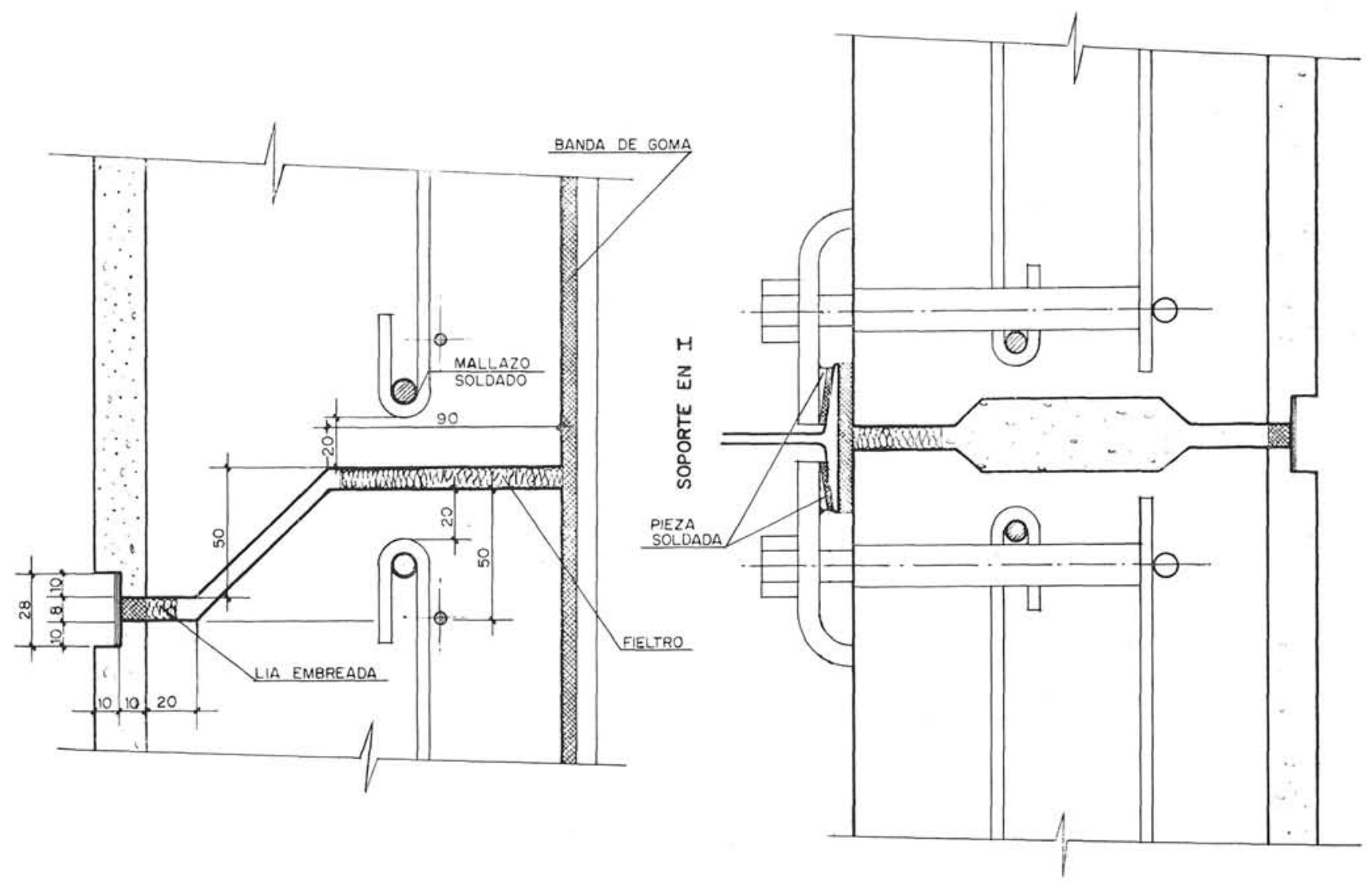

realizó en forma continua, durante 11 horas, no dejándose, por tanto, juntas intermedias, y con el auxilio de un enérgico vibrado para facilitar el paso del hormigón a través de cerca de $40.000 \mathrm{~kg}$ de acero corrugado que formaba las armaduras de la losa.

Se cuidó especialmente el curado posterior, manteniéndose una lámina de agua sobre toda la losa durante veintiocho días y riegos muy frecuentes durante cuarenta días más.

La nave entró en servicio en mayo de 1967 y fue inaugurada oficialmente el 24 de abril de 1968.
G. ECHEGARAY COMBA
Dr. Arquitecto.
A. GARCIA MESEGUER,
Dr. Ingeniero de Caminos.

La nueva nave de Ensayos Mecánicos del Instituto Eduardo Torroja es el resultado de la colaboración de todos los técnicos del Centro, coordinados por su Director, el Dr. Ing. de Caminos D. Jaime Nadal. De forma especialmente activa, en lo que se refiere al proyecto y ejecución, han intervenido los Drs. Arquitectos Echegaray, Aguirre, Jenaro y Monterde; los Drs. Ings. de Caminos Batanero, Fernández y Martínez Calzón, y el Aparejador Rodríguez Ginestal.

También deben citarse, por haberles correspondido prestar una especial colaboración, los siguientes técnicos: Benjamín Gutiérrez, Guillermo Sulzberger y Rafael Martín Fito.

La ejecución material de la nave corrió a cargo de la Empresa Agromán, estando al frente de la obra los Ings. Gascón y Díaz del Río, y el Encargado Pablo Ibáñez. 


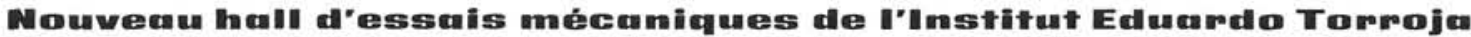

Cet important ouvrage satisfait l'urgente nécessité qu'avait l'Institut Eduardo Torroja de disposer d'un hall d'essais mécaniques, capable d'admettre dans une large mesure tous les types d'essais prévisibles dans un proche avenir.

L'expérience acquise au cours des années de service du hall primitif dont disposait déjà ce Centre a été appliquée à la construction du nouveau. Cet ouvrage consiste fondamentalement en une structure métallique, de $33 \mathrm{~m} 50 \times$ $\times 11 \mathrm{~m} 50$ et $8 \mathrm{~m}$ de hauteur. La façade est constituée de panneaux préfabriqués spéciaux type LECA. L'intérieu renferme une puissante dalle en béton armé, de $10 \mathrm{~m} 50 \times 25 \mathrm{~m} 50$ et $1 \mathrm{~m} 20$ d'épaisseur, percée par 270 points d'ancrage, de 50 et $100 \mathrm{t}$ - pouvant travailler isolément ou en groupe-, appuyée sur deux murs du même matériau, de $80 \mathrm{~cm}$ d'épaisseur. Le sous-sol permet les actions interdépendantes communes au-dessus et au-dessous de la dalle, les ancrages permettant la communication entre leurs parties supérieure et inférieure. Ont été également prévus un éclairage soigneusement pensé et l'accès de véhicules lourds au hall et au sous-sol. Un pont roulant de $10 \mathrm{t}$, ayant accès aux deux zones, a été installé, et il est possible d'en installer un second de même puissance. Tous les calculs ont été réalisés à l'aide du computeur électronique de l'I.E.T.c.c.

Cet ouvrage remarquable est l'un des plus importants de son genre en Europe.

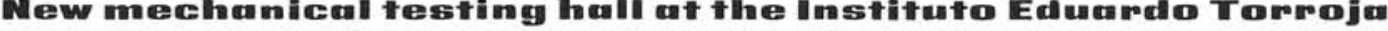

This important building meets an urgent need at the Institute Eduardo Torroja to have a mechanical testing hall that is capable of dealing with all kinds of tests that are likely to arise in the foreseeable future.

In designing it account has been taken of all requirements anticipated as a result of the experience obtained during the use of the earlier testing hall which the Institute already has. The new testing hall consists essentially
of a metallic structure, $33.50 \mathrm{~m}$ high, $11.50 \mathrm{~m}$ wide and $8 \mathrm{~m}$ high, enclosed by prefabricated LECA type panels. The hall has a powerful reinforced concrete slab, $11.50 \mathrm{~m}$ wide and $25.50 \mathrm{~m}$ long, which is $1.20 \mathrm{~m}$ thick. The slab has 270 anchorage points, with a load capacity of $50 \mathrm{t}$ and $100 \mathrm{t}$ each. These points can be loaded singly, or in groups. The slab rests on two lateral reinforced concrete walls, of $80 \mathrm{~cm}$ thickness. Below the slab there is a basement, The slab rests on two lateral reinforced concrete walls, of $80 \mathrm{~cm}$ thickness. Below the slab there is a basement, which can be used in conjunction with the hall above for testing purposes, since the anchorage points make it possible to communicate both sides of the slab. A careful system of illumination has also been provided, and heavy vehicles can enter both the basement and the main hall. One ten ton bridge crane has been installed, although two such cranes can be fitted. All calculations have been done with the aid of the electronic computer of the I.E.T.c.c.

The total design makes this project one of the most important of its type in Europe.

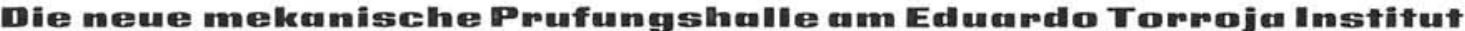

Diese neue Halle wird den Eduardo Torroja Institut ermöglichen aller Art mechanische Prüfungen in den nächsten Jahren auszuführen.

Die Experienz welches der Institut mit der alten Mechanischeprüfungshalle gehabt hat wurde vollkommend in der neue Halle angewendet.

Die Halle ist eine metalische Struktur, $33,50 \mathrm{~m}$ lang, $11,50 \mathrm{~m}$ breit und $8 \mathrm{~m}$ hoch, welche mit prefabrizierte LECA Betonstücke eingeschlossen ist. Die Halle hat eine mächtige Stahlbetonplatte, welche $10,50 \times 25,50 \times 1,20 \mathrm{Gross}$ ist, und mit 270 Angriffspunkte besorgen wird. An jeder Angriffspunkt kann eine Kraft von entweder 50 Ton oder 100 Ton angewendet werden. Die Platte liegt auf zwei Stahlbeton Seitenmauern, welche $80 \mathrm{~cm}$ dick sind.

Under der Platte wurde eine Niederhalle gebaut, die mit der Grosshalle in Beziehung steht, so dass man Prüfungs arbeiten über und unter der Platte zur gleicher Zeite durchführen kann.

Die Halle ist sorgfältigerweise beleuchtet, und die Schwehrwagen können in der Unter sowohl in der Grosshalle hineinfähren. Ein 10 tönniger Kran ist schon aufgestellt, und es ist möglich auch ein zweiter Krangleicher Kraft, aufzusetzen.

Alle die Berechnungen dieser Halle wurden elektronischerweise in der Institut ausbearbeitet.

Im Zusammenhang ist diese merkwürdige Halle einer der wichtigsten Europas. 